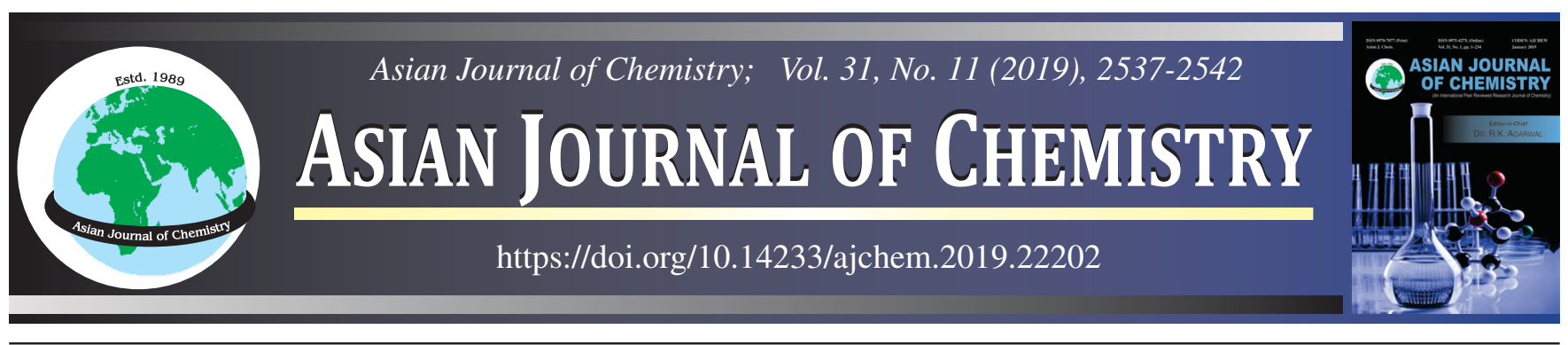

\title{
Study of Ratio Variation of Binary Components of Cross Linking Agent on Extent of Polymerization and Mechanical Properties of Polyurethane Composites
}

\section{A. Sharma*, S.K. Sharma and A. Rani}

Department of Pure and Applied Chemistry, University of Kota, Kota-324005, India

*Corresponding author: E-mail: ankit@uok.ac.in

Received: 18 May 2019; Accepted: 15 June 2019;

Polyethylene glycol based polyurethane polymer and its fly ash reinforced polyurethane composite were prepared by optimizing the concentration ratio of binders, cross linking agents and curing agents. The components ratio of cross linking agents with the same hydroxyl functionalities i.e. 1,4-butane diol and 1,1,1-trimethylol propane affects the mechanical properties of polymer. The extent of polymerization of polyurethane matrix and fly ash reinforced polyurethane composite was found to be independent of the component ratio of cross linking agents. PEG based polyurethane polymer and their fly ash-reinforced composite can be synthesized at particular ratio by mass of cross linking agents i.e. 0.5 keeping constant w/w ratio $3: 2$ of binders and curing agents. Effect of w/w ratio variation of cross linking agents on the extent of polymerization has been studied through SEM technique. Cross linking agents, curing agents and polyurethane composite have been characterized by IR spectra. Effect of w/w ratio variation of binary components 1,4-butane diol and 1,1,1-trimethylol propane of cross linking agents on the mechanical properties of fly ash-reinforced polyurethane composite has been studied by evaluating tensile strength and Young modulus of composite material by universal testing machine. Hardness of fly ashreinforced polyurethane composite with different ratio of 1,4-butane diol and 1,1,1-trimethylol propane of cross linking agents was evaluated by durometer.

Keywords: Binders, 1,4-Butanediol, Fly ash, Curing agents, Cross linking agent, Polyethylene glycol, Polyurethane composite.

\section{INTRODUCTION}

On the basis of physical properties, solid polymers can be elastomers, thermoplastics and thermosetting. Cross linking is a chemical bond between polymer chain other than at ends, cross linking determines physical properties as, they increases the molecular weight and limits the translational motions of the chains with respect to each others. Only few cross-links can minimize the solubility of a polymer and can make gel polymer which is insoluble and can absorb solvents in which the uncross polymer is soluble, as the cross linking increases, chain will not allow the solvent molecules to enter into the spaces between the chains [1].

Polyurethane composites having fillers [2,3] for various endeavors like wear resistance, environment stability, flame retardant and others. Present polymeric materials envisage the bulk utility of the hazardous waste fly ash by synthesizing fly ash-reinforced polyurethane composites using homogenous mixture of 1,4-butane diol and 1,1,1-trimethylol propane as cross linking agents. Filler loading effects the gelation time wherein high concentration of the filler enhances the viscosity, which minimizes the molecular motion. Excessive filler concentration adversely affects the extent of polymerization as it hinders the contact between the unreacted reactants and prepolymer.

In present work, polymeric matrix synthesis uses polyethylene glycol-600 as binder [4,5], homogenous mixtures of diols (1,4-butane diol) and triols (1,1,1-trimethylol propane) as cross linking agents $[6,7]$ in different $w / w$ ratios and toluene 2,4-diisocyanat as curing agent. Optimized condition for complete polymerization in synthesis of polyurethane matrix and fly ash reinforced polyurethane composites was mainly studied by keeping 3:2 w/w ratio of binders and curing agents constant and varying the $\mathrm{w} / \mathrm{w}$ ratio of binary components of cross linking agents and ratio of cross linking agents itself with respect to binders and curing agents [8]. Effect of w/w

This is an open access journal, and articles are distributed under the terms of the Attribution 4.0 International (CC BY 4.0) License. This license lets others distribute, remix, tweak, and build upon your work, even commercially, as long as they credit the author for the original creation. You must give appropriate credit, provide a link to the license, and indicate if changes were made. 
ratio of binary components (1,4-butane diol and 1,1,1-trimethylol propane) of cross linking agents on mechanical properties of fly ash-reinforced polyurethane composites was also the part of present study.

\section{EXPERIMENTAL}

For polyurethane composite synthesis binders: PEG 600, curing agent: toluene 2,4-diisocyanate (TDI) and cross linkagers [9]: 1,4-butane diol, 1,1,1-trimethylol propane were used of AR grade (Sigma Aldrisch). Drying process applied at 105 ${ }^{\circ} \mathrm{C}$ to remove any water content in isocyanate so that no reaction occurs between isocyanate and water that can form $\mathrm{CO}_{2}$ bubbles otherwise it causes deformity in the polymer. Wooden mold material for casting was used, AL-40 (ALFA-40, JIVIKA company New Delhi) a silicon spray is used as a mold release.

The cured polyurethane-foams were cut as per the ASTMD638 Type I standards for mechanical testing by Universal testing machine UTE-40 (FiE make, NEI limited, Gujrat)

Filler fly ash waste material [10] was dried at $110^{\circ} \mathrm{C}$ for $2.5 \mathrm{~h}$ to remove any humidity, which can cause bubble formation and may degrade the quality of polymer material.

\section{General procedure}

Polyurethane synthesis [11]: (a) Experimental mixing of different composite formulation was carried out by hand mixing in a beaker taking care that no air bubble gets entrapped inside the mix. Liquid ingredients (PEG-600, 1,4-butane diol and 1,1,1-trimethylol propane [12]) were charged in a beaker, the whole mass was mixed for $0.5 \mathrm{~h}$ and later fly ash was added to the mix, stirred to form a homogenous paste, later subjected to vacuum to drive the entrapped air out. Cross linkage is essential part of polymer synthesis wherein the chain of polymers are interlocked for which diols and triols of cross linking agents having specific weight ratio (1:2,2:1 and 1:1) have been used in the present work.

(b) Drying process was performed at $105^{\circ} \mathrm{C}$ to remove any moisture contents in curing agents (TDI) to check undesired chemical reactions between isocyantes and water, which develops carbon dioxide bubbles making highly porous polyurethanefoam.

(c) TDI was added to the polyol system and mixing was carried out for another 1-2 min.

(d) Whole resin mass (binders and cross linking agents) with curing agents after mix is subjected to wooden mold pre applied with mold release AL-40. After curing polyurethanecomposite [13-15] was removed from mold and left for seven days for complete curing process. Samples were prepared as per the ASTMD638 Type I.

Function of the curative agent is to link the $\mathrm{OH}$ of the binder (hydroxyl compound) with NCO of the curative agent [16] (isocyanate compound) other liquid additive in the composite mixture may have $\mathrm{OH}$ equivalent and need to be taken into account for calculating the amount of the curing agent.

$$
\mathrm{EW}=\frac{5600}{\text { Hydroxyl number }}=\frac{1000}{\text { Hydroxyl value }}=\frac{1700}{\% \mathrm{OH}}
$$

Equivalent weight (EW) for isocyanate compound [TDI, diphenylmethane diisocyanate (MDI), etc.].

$$
\mathrm{EW}=\frac{4200}{\% \mathrm{NCO}}
$$

The equivalent weight of binder and curative agent is evaluated and ratio is optimized for the polyurethane synthesis.

$$
\mathrm{W}_{\text {curative }}=(\mathrm{IR})\left(\mathrm{EW}_{\text {curative }}\right)\left(\sum \frac{\mathrm{W}_{\mathrm{n}}}{\mathrm{EW}_{\mathrm{n}}}\right)
$$

$\mathrm{W}_{\text {curative }}=$ weight $($ mass $)$ of curative agent $(\mathrm{g}) ; \mathrm{EW}_{\text {curative }}=\mathrm{NCO}$ equivalent weight of curative; $\mathrm{W}_{\mathrm{n}}=$ Weight (mass) of each liquid compound; $\mathrm{EW}_{\mathrm{n}}=\mathrm{OH}$ equivalent weight for each liquid; $\mathrm{IR}=$ index ratio of $\mathrm{NCO}$ to $\mathrm{OH}$.

On the basis of above calculations the $\mathrm{w} / \mathrm{w}$ ratio selected for the matrix formulation is 3:2 of binders and curing agents [17], respectively.

Too much curative agent or too less will degrade the requisite mechanical properties of the polymer. Slight concentration of water (about $0.01 \%$ shall require $0.16 \mathrm{~g}$ more amount of curative agent. So the filler (fly ash) and curing agents shall be made free from the moisture before using them for the polyurethane composite synthesis.

Characterization: Hardness [18,19] of fly ash-reinforced polyurethane-composites was evaluated by durometer. Tensile strength, Young modulus, were evaluated by universal testing machine, UTE-40 (NEI, Vadodara). SEM (ZEISS, Germany) of selected samples was done for evaluation of the cell morphology and filler dispersion in the fly ash-reinforced polyurethane composites. Relationship between SEM study and extent of polymerization was used to show effect of w/w ratio of cross linking agents at constant w/w ratio of binders and curing agents. Characterization of cross linking agents components (1,4-butane diol and 1,1,1-trimethylol propane) and their mixture thereof, binders (PEG-600) curing agents (TDI), polyurethanecomposites, was done by ATR (ALPHA, Bruker, USA) and FTIR (TENSOR27, Bruker, USA).

\section{Spectroscopic characterization of cross linking agents, curing agents, polyurethane-foam}

The binary component (1,1,1-trimethylol propane and 1,4butane diol) of cross linking agents have a common characterizing peak for $\mathrm{OH}$ group around $3600-3200 \mathrm{~cm}^{-1}$. 1,4-Butanediol has two peaks (symmetric and asymmetric stretching bands) of methylene only around $2925 \mathrm{~cm}^{-1}$. While 1,1,1-trimethylol propane is showing two extra stretching bands of methyl along with methylene around $2925 \mathrm{~cm}^{-1}$. Cross linking agents homogenous mixture of 1,4-butane diol and 1,1,1-trimethylol propane shows the characteristic peaks of $\mathrm{OH}$ around 3200 $\mathrm{cm}^{-1}$ and methyl along with methylene $2925 \mathrm{~cm}^{-1}$ with 1450 $\mathrm{cm}^{-1}$ of methyl group.

The curing agent TDI used in experiment is characterized by the presence of stretching band of $-\mathrm{N}=\mathrm{C}=\mathrm{O}$ functional group around $2249 \mathrm{~cm}^{-1}$ and $-\mathrm{C}=\mathrm{C}$-stretching bands of benzene ring around $1611,1578,1522 \mathrm{~cm}^{-1}$, the peaks characterizing the curing agents signifies the aromatic nature of curing agents, the chain extender used in the experiment is PEG-600, presence of broad and less intense peak around $3600-3200 \mathrm{~cm}^{-1}$ indicates the presence of hydroxyl group, while strong and intense peak around $2925 \mathrm{~cm}^{-1}$ shows the presence of methylene as a part of polymeric chain. 
The polyurethane foam formed after the reaction of $\mathrm{OH}$ functionality of binders and cross linking agents with $\mathrm{NCO}$ functionalities of the curing agents is characterized by the formation of urethane links -NHCOO-, indicated by the IR peaks for $\mathrm{N}-\mathrm{H}$ stretching band around $3309 \mathrm{~cm}^{-1}$ and $\mathrm{C}=\mathrm{O}$ stretching around $1711 \mathrm{~cm}^{-1}$.

\section{RESULTS AND DISCUSSION}

Effect of concentration ratios (w/w) of components of cross linking agent in the extent of polymerization of fly ash reinforced polyurethane composites

The polyols of cross linking agents i.e. 1,4-butane diol [20] and 1,1,1-trimethylol propane [21] were taken in the ratio $2: 1(\mathrm{w} / \mathrm{w})$. It was found that incomplete polymerization takes place when $16.66 \%(\mathrm{w} / \mathrm{w})$ cross linking agents was taken however cross linking agents with $9.09 \%(\mathrm{w} / \mathrm{w})$ results in the formation of the polyurethane matrix and composite thereof, this composition was suitable for the fly ash-reinforced composite synthesis, provided the ratio by mass of BN:CRA::3:2 (Table-1). The extent of polymerization was analyzed by the SEM image wherein the agglomeration of filler fly ash is seen in the matrix (Fig. 1) at $16.66 \%$ (w/w) of cross linking agents representing the incomplete polymerization, while SEM image in Fig. 2 at $9.09 \%$ (w/w) of cross linking agents concludes the complete polymerization wherein the filler fly ash is uniformly distributed in the polyurethane matrix, both having 2:1 (w/w) ratio by mass of 1,4-butane diol and 1,1,1-trimethylol propane with $3: 2$ ratio (w/w) of binders and curing agents.

The ratio of polyols of cross linking agents (1,4-butane diol [20] and 1,1,1-trimethylol propane [21-25]) was reversed in the second experiment with w/w ratio of BD:TMP::1:2. It was found that no polymerization takes place when $16.66 \%$ cross linking agents was used. However cross linking agents at $9.09 \%$ results in the synthesis of the polyurethane at the same ratio by mass of BN:CRA::3:2 (Table-2). The extent of polymerization can be analyzed by the SEM image wherein the cluster of filler fly ash restricted to a small domain is seen in the polyurethane matrix (Fig. 3) at $16.66 \%$ (w/w) of cross linking agents representing the incomplete polymerization, SEM image in Fig. 4 at $9.09 \%$ (w/w) of cross linking agents concludes the complete polymerization wherein the filler fly ash is uniformly distributed in the polyurethane matrix, both having 1:2 (w/w) ratio by mass of 1,4-butane diol and 1,1,1-trimethylol propane with $3: 2$ ratio $(w / w)$ of binders and curing agents.

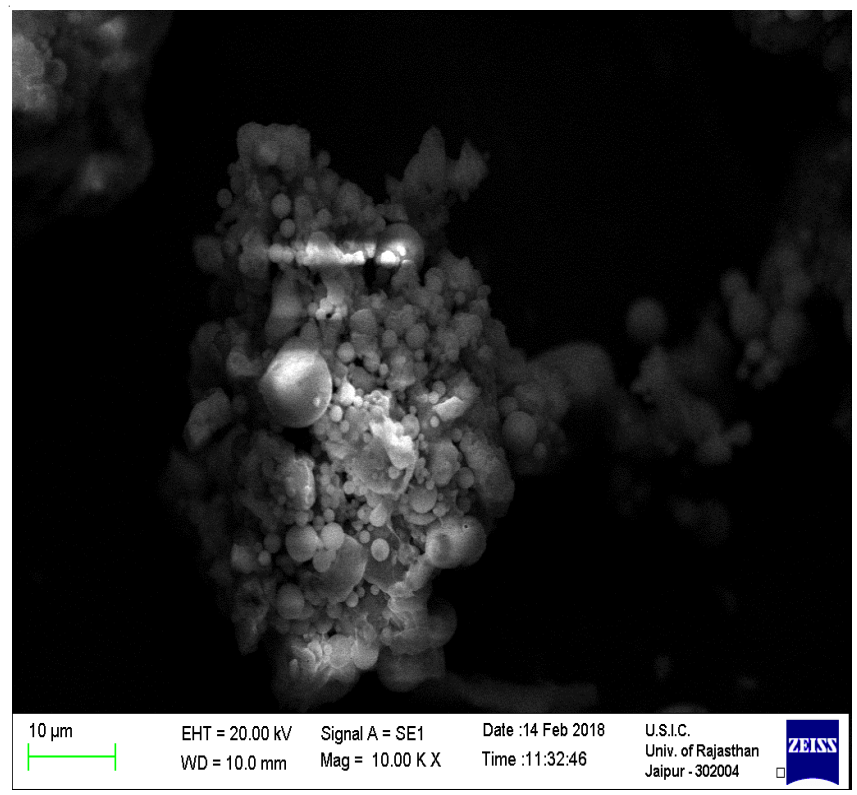

Fig. 1. SEM image showing the incomplete formation of the fly ash reinforced polyurethane composite (fly ash clumping in polyurethane matrix)

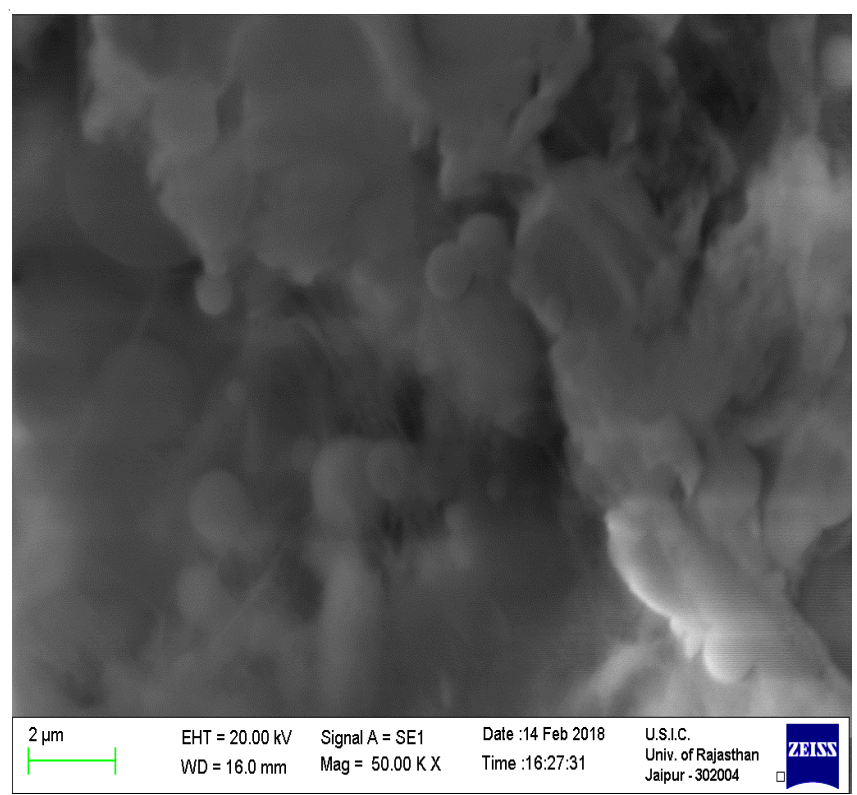

Fig. 2. SEM image showing the formation of the fly ash reinforced polyurethane composite (uniform distribution of fly ash in polyurethane matrix)

TABLE-1

EFFECT ON POLYMERIZATION BY VARYING THE CONCENTRATION RATIO BY MASS OF CROSS LINKING AGENTS AT CONSTANT CONCENTRATION RATIO 2:1 BY MASS OF 1,4-BUTANE DIOL (BD) AND 1,1,1-TRIMETHYLOL PROPANE (TMP)

\begin{tabular}{ccccc}
\hline BD:TMP $(w / w)$ & Cross linking agents (wt \%) & Binders (wt \%) & Curing agents (wt \%) & Result \\
\hline $2: 1$ & 16.66 & 50.00 & 33.33 & Incomplete polymerization \\
$2: 1$ & 9.09 & 54.54 & 36.36 & Complete polymerization \\
\hline
\end{tabular}

TABLE-2

EFFECT ON THE EXTENT OF POLYMERIZATION BY VARYING THE CONCENTRATION RATIO BY

MASS OF CROSS LINKING AGENTS AT CONSTANT CONCENTRATION RATIO1:2 BY MASS OF 1,4-BUTANE DIOL (BD) AND 1,1,1-TRIMETHYLOL PROPANE (TMP)

\begin{tabular}{ccccc}
\hline BD:TMP $(w / w)$ & Cross linking agents $(w t \%)$ & Binders $(w t \%)$ & Curing agents (wt \%) & Result \\
\hline $1: 2$ & 16.66 & 50.00 & 33.33 & Incomplete polymerization \\
$1: 2$ & 9.09 & 54.54 & 36.36 & Complete polymerization \\
\hline
\end{tabular}




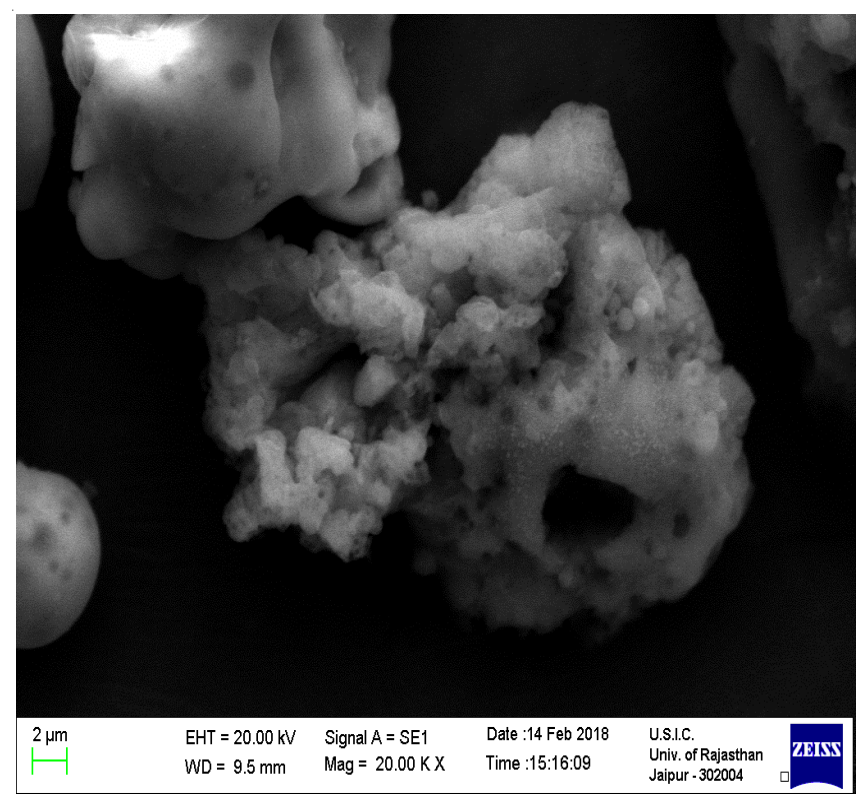

Fig. 3. SEM image showing the incomplete formationof the fly ash reinforced polyurethane composite. (fly ash clustering in polyurethane matrix)

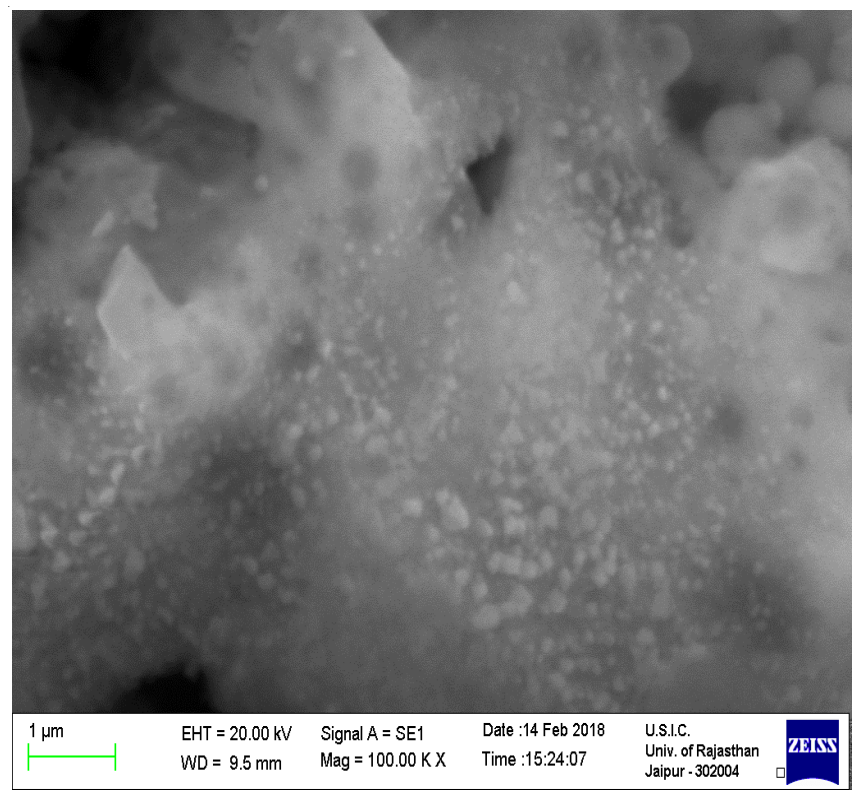

Fig. 4. SEM image showing the formation of the fly ash reinforced polyurethane composite (uniform distribution of fly ash in polyurethane matrix)

In the third experiment the ratio of polyols of cross linking agents i.e. BD:TMP::1:1 (w/w) was taken, it was found that the synthesis of the polyurethane-polymerization take place with the cross linking agents weight percent as $9.09 \%$ whilst incomplete polymerization with the cross linking agents 16.66 $\%$ was noticed The same matrix was used for the synthesis of the fly ash-reinforced composite, provided the ratio by mass of BN:CRA::3:2. (Table-3). The extent of polymerization was analyzed by the SEM image where clumping of filler fly ash restricted to a small domain is seen in the polyurethane matrix (Fig. 5) at $16.66 \%$ (w/w) of cross linking agents representing the incomplete polymerization, SEM image in Fig. 6 at $9.09 \%$ (w/w) of cross linking agents concludes the complete polymerization wherein the filler fly ash is uniformly distributed in the

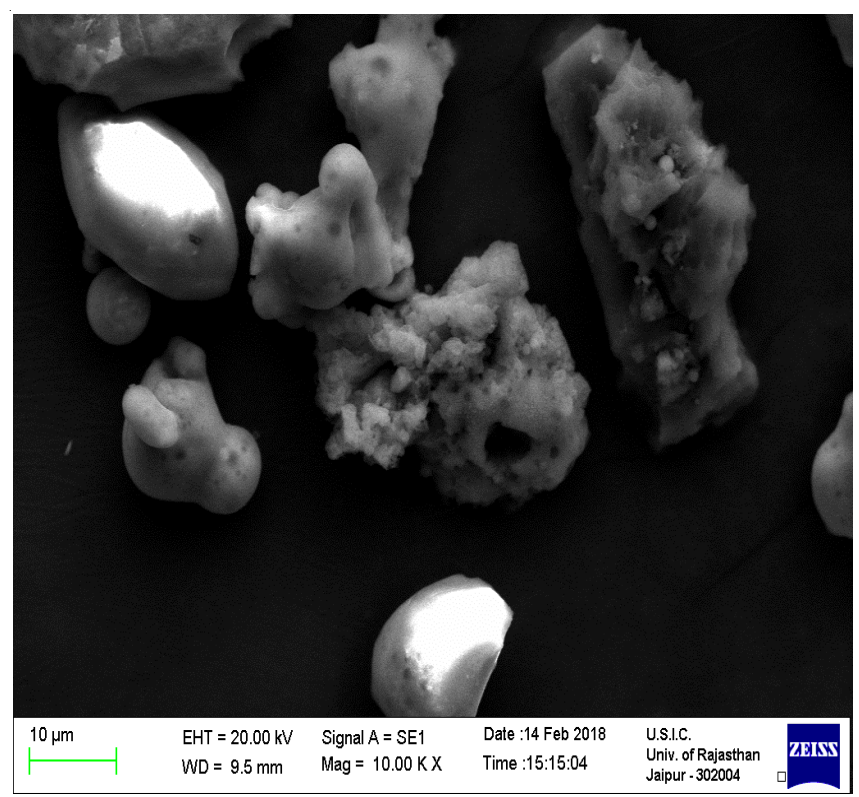

Fig. 5. SEM image showing the incomplete formation of the fly ash reinforced polyurethane composite.(agglomeration of fly ash in polyurethane matrix)

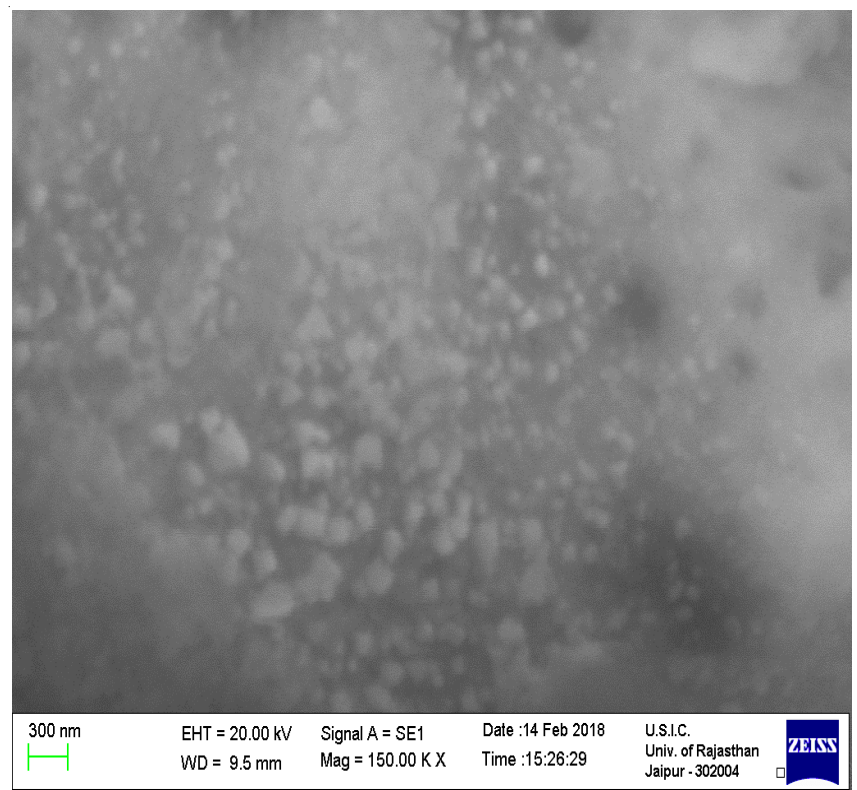

Fig. 6. SEM image showing the formation of the fly ash reinforced polyurethane composite (uniform distribution of fly ash in polyurethane matrix)

TABLE-3

EFFECT OF POLYMERIZATION BY VARYING THE CONCENTRATION RATIO BY MASS OF CROSS LINKING AGENTS AT CONSTANT CONCENTRATION RATIO 1:1 BY MASS OF 1,4-BUTANE DIOL AND (BD) 1,1,1-TRIMETHYLOL PROPANE (TMP)

\begin{tabular}{ccccc}
\hline BD:TMP $(w / w)$ & Cross linking agents (wt \%) & Binders (wt \%) & Curing agents (wt \%) & Result \\
\hline $1: 1$ & 16.66 & 50.00 & 33.33 & Incomplete polymerization \\
$1: 1$ & 9.09 & 54.54 & 36.36 & Complete polymerization \\
\hline
\end{tabular}


polyurethane matrix, both having 1:1 (w/w) ratio by mass of 1,4-butane diol and 1,1,1-trimethylol propane with 3:2 ratio (w/w) of binders and curing agents.

The effective polymerization for the synthesis of polyurethane based matrix and its fly ash reinforced composite thereof was when the ratio of concentration by mass of $\mathrm{BN}$ :CRA:CLA $:: 3: 2: 0.5$ or by weight percent as $9.09 \%$ (cross linking agents), $54.54 \%$ (PEG), $36.36 \%$ (TDI) no matter cross linking agents which is the binary mixture of 1,4-butane diol and 1,1,1-trimethylol propane was of w/w ratio by mass as $1: 1$ or $1: 2$ or $2: 1$. The above experiments gives the remarkable ratio of cross linking agents by mass as 0.5 and by weight percent $9.09 \%$ in formulation of polyurethane matrix and composites which is independent of the ratio by mass of the binary components of cross linking agents.

Effect of cross linking agents binary component ratios on mechanical properties $[10,26]$ of fly ash-reinforced composites: Fig. 7 shows the tensile strength and young modulus (33 MPA and 16.5 GPA) of fly ash reinforced polyurethane composites with binary component wt. ratio 1:1 of 1,4-butane diol and 1,1,1-trimethylol propane of cross linking agents. Fig. 8 shows the tensile strength and Young modulus (28 MPA

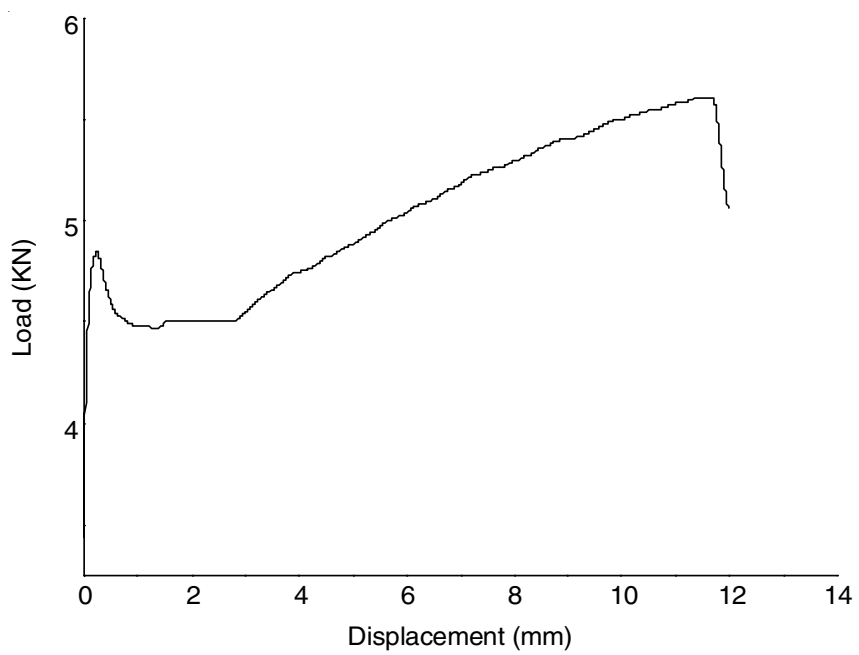

Fig. 7. Load vs. displacement for polyurethane composite at $1: 1 \mathrm{w} / \mathrm{w}$ ratio of 1,4-butane diol and 1,1,1-trimethylol propane

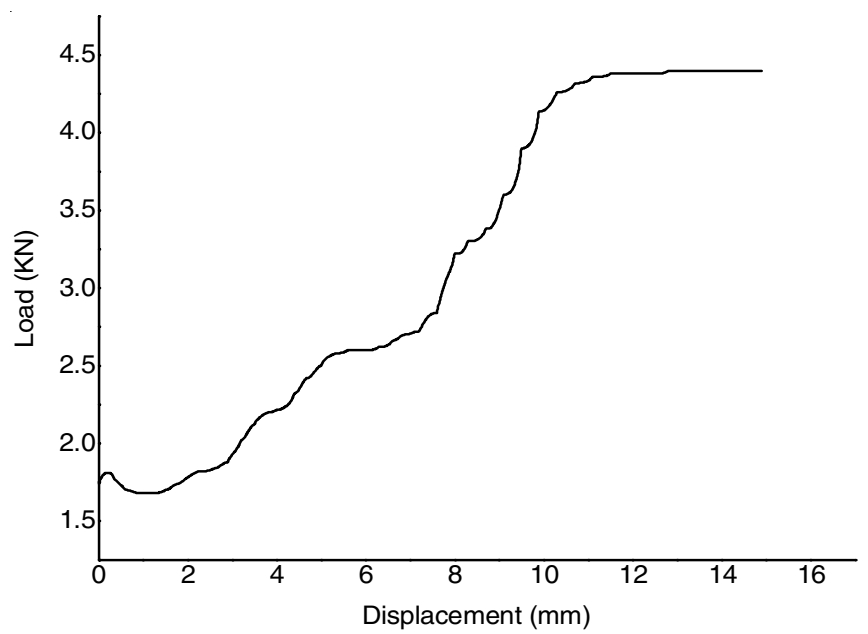

Fig. 8. Load $v s$. displacement for polyurethane composite at 1:2 w/w ratio of 1,4-butane diol and 1,1,1-trimethylol propane and 14 GPA) of fly ash reinforced polyurethane composites with binary component ratio of cross linking agents as 1:2 (BD:TMP) and Fig. 9 shows tensile strength; 13 MPA and Young modulus 6.5 GPA of fly ash reinforced polyurethane composites with binary component ratio of cross linking agents as $2: 1$ (BD:TMP).

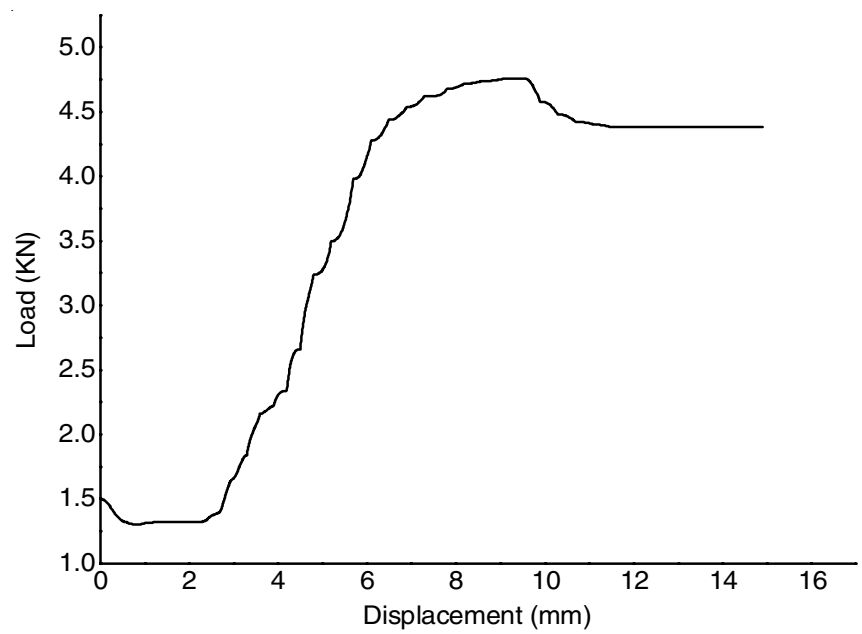

Fig. 9. Load $v s$. displacement for polyurethane composite at 2:1 w/w ratio of 1,4-butane diol and 1,1,1-trimethylol propane

Mechanical properties viz. tensile strength (TS), Young modulus (YM) and hardness were evaluated for fly ash reinforced polyurethane composite and were found to depend on the wt/wt ratio of binary components of cross linking agents (Table-4).

\begin{tabular}{cccc}
\multicolumn{5}{c}{ TABLE-4 } \\
TENSILE STRENGTH, YOUNG MODULUS AND \\
HARDNESS OF POLYURETHANE COMPOSITE \\
\hline BD:TMP & $\begin{array}{c}\text { Tensile strength } \\
\text { (MPA) }\end{array}$ & $\begin{array}{c}\text { Young modulus } \\
\text { (GPA) }\end{array}$ & Hardness (HRI) \\
\hline $1: 1$ & 33 & 16.5 & 52 \\
$1: 2$ & 28 & 14.0 & 76 \\
$2: 1$ & 13 & 6.5 & 38 \\
\hline
\end{tabular}

\section{Conclusion}

The polyurethane matrix and fly ash-reinforced polyurethane composite complete polymerization is independent of the ratio of 1,4-butane diol and 1,1,1-trimethylol propane in cross linking agents while depends on the wt \% of cross linking agents in the mixture. The mechanical properties of fly ashreinforced polyurethane composite depends on the (w/w) ratio of 1,4-butane diol and 1,1,1-trimethylol propane of cross linking agents.

\section{CONFLICT OF INTEREST}

The authors declare that there is no conflict of interests regarding the publication of this article.

\section{REFERENCES}

1. J. Maitra and V.K. Shukla, Am. J. Polym. Sci., 4, 25 (2014); https://doi.org/10.5923/j.ajps.20140402.01.

2. G.K. Latinwo, D.S. Aribike, L.O. Oyekunle, A.A. Susu and S.A. Kareem, Nat. Sci., 8, 92 (2010). 
3. G.C. Onuegbu and I.O. Igwe, Mater. Sci. Appl., 2, 810 (2011); https://doi.org/10.4236/msa.2011.27110.

4. C. Tan, T. Tirri and C.E. Wilen, Polymers, 9, 184 (2017); https://doi.org/10.3390/polym9050184.

5. D.K. Chattopadhyay, B. Sreedhar and K.V.S.N. Raju, Ind. Eng. Chem. Res., 44, 1772 (2005); https://doi.org/10.1021/ie0492348.

6. S. Mane, S. Ponrathnam and N. Chavan, Can. Chem. Trans., 3, 473 (2015);

https://doi.org/10.13179/canchemtrans.2015.03.04.0245.

7. C.P.M. Kutty, T.M. Nair, G. Unnikrishnan and M. Jahfar, Sci. Rev. Chem. Commun., 3, 62 (2013).

8. R. Gogoi, U.K. Niyogi, M.S. Alam and D.S. Mehra, World Appl. Sci. J., 21, 276 (2013).

9. H. Janik and G.J. Vancso, Polimery, 50, 139 (2005).

10. I. Ahmad and P.A. Mahanwar, J. Miner. Mater. Charact. Eng., 9, 183 (2010); https://doi.org/10.4236/jmmce.2010.93016.

11. A.M. Azman, A. Baharum and K.H. Badri, Polym. Polym. Compos., 24, 789 (2016); https://doi.org/10.1177/096739111602400916.

12. S.A. Guelcher, K.M. Gallagher, J.E. Didier, D.B. Klinedinst, J.S. Doctor, A.S. Goldstein, G.L. Wilkes, E.J. Beckman and J.O. Hollinger, Acta Biomater, 1, 471 (2005); https://doi.org/10.1016/j.actbio.2005.02.007.

13. D.S. Aribike, G.K. Latinwo and A.A. Susu, J. Sci. Technol. Environ., 7, 25 (2007)

14. I. Javni, W. Zhang, V. Karajkov, Z.S. Petrovic and V. Divjakovic, J. Cell. Plast., 38, 229 (2002); https://doi.org/10.1177/0021955X02038003139.
15. S. Clauß, J. Gabriel, A. Karbach, M. Matner and P. Niemz, Holzforschung, 65, 835 (2011); https://doi.org/10.1515/HF.2011.095.

16. A. Lapprand, F. Boisson, F. Delolme, F. Méchin and J.P. Pascault, Polym. Degrad. Stab., 90, 363 (2005); https://doi.org/10.1016/j.polymdegradstab.2005.01.045.

17. R. Gogoi, Int. J. Basic Appl. Sci., 3, 118 (2014).

18. S.L. Huang and J.Y. Lai, J. Mater., 27, 1563 (1997).

19. Z.S. Petrovic, M. Ilavski, K. Dusek, M. Vidakovic, I. Javni and B. Banjanin, J. Appl. Polymer Sci., 50, 391 (1991); https://doi.org/10.1002/app.1991.070420211.

20. S. Brzic, V. Rodic, M. Dimic, D. Simic, L. Jelisavac and M. Bogosavljevic, Sci. Technol. Rev., 65, 55 (2015); https://doi.org/10.5937/STR1503055B.

21. A. Dey, M.A.S. Khan, J. Athar, A.K. Sikder and S. Chattopadhyay, J. Mater. Sci. Eng. B, 5, 145 (2015); https://doi.org/10.17265/2161-6221/2015.3-4.005.

22. S.R. Jain, J. Sci. Ind. Res. (India), 61, 899 (2002).

23. T. Peijs, R.J.M. van Vught and L.E. Govaert, Composite, 26, 83 (1995); https://doi.org/10.1016/0010-4361(95)90407-Q.

24. O.I. Oluwole and O.M. Avwerosuoghene, Int. J. Eng. Technol. Innov., 5, 255 (2015).

25. K. Choo, Y.C. Ching, C.H. Chuah, S. Julai and N.S. Liou, Materials, 9, 644 (2016) https://doi.org/10.3390/ma9080644.

26. M. Singla and V. Chawla, J. Miner. Mater. Charact. Eng., 9, 199 (2010); https://doi.org/10.4236/jmmce.2010.93017. 